\title{
Combination of $\beta$-Blocker and Milrinone for Acute Heart Failure
}

\author{
Yoshio Yasumura, MD, $\mathrm{PhD}$
}

$\mathbf{M}$ ultiple major registries and trials, such as ADHERE, ${ }^{1}$ OPTIME-CHF trial, ${ }^{2}$ and the ESCAPE trial, ${ }^{3}$ have reported that inotropic agents fail to demonstrate beneficial clinical outcome in patients with acute heart failure (AHF). The OPTIME-CHF trial enrolled patients with severe chronic HF, but the administered inotropic therapy was reported as inessential in the treatment of AHF. No benefit from milrinone treatment was observed in the number of hospital days or other measurements showing improvement of HF. The negative effects of milrinone are likely a consequence of widespread phosphorylation of $\mathrm{Ca}^{2+}$-handling proteins by cAMP. Although this provides inotropy, excessive catecholamine stimulation is an adverse effect because of the effect on excitationcontraction coupling, electrophysiology, or remodeling. In the OPTIME-CHF trial, patients were randomly assigned to receive a 48 -h infusion of either milrinone $\left(0.5 \mu \mathrm{g} \cdot \mathrm{kg}^{-1} \cdot \mathrm{min}^{-1}\right.$ or saline placebo. This dose of milrinone is obviously higher than that routinely used in Japan (ie, 0.125 or $0.25 \mu \mathrm{g} \cdot \mathrm{kg}^{-1} \cdot \mathrm{min}^{-1}$ ). Although high-dose inotropic agents can be cardiotoxic and have failed to show beneficial effects beyond short-term hemodynamic improvement, more studies are required to elucidate the effectiveness of low-dose inotropic agents in patients with AHF.

\section{Article p 1646}

In the setting of AHF, inotropic agents are only recommended in patients with systolic HF with systolic blood pressure (SBP) $<90 \mathrm{mmHg}$ and evidence of inadequate organ perfusion despite other therapeutic interventions. It is also reasonable to use inotropes in patients with worsening cardiorenal syndrome despite intravenous diuretics and vasodilator therapy. We often use a combination of low-dose dobutamine and milrinone when we expect certain inotropism with less complications than increasing the doses of single drugs in these patients with severe left ventricular dysfunction.

In this issue of the Journal, Kobayashi et $\mathrm{al}^{4}$ propose an interesting application of milrinone. Landilol, which is ultra-shortacting, has strong $\beta$-selectivity, and has preferential negative chronotropism compared with negative inotropism, was one of the $\beta$-blockers used in this study as adjunctive therapy when standard therapy with milrinone was not effective at slowing the heart rate (HR). To date, combination therapy of $\beta$-blocker and phosphodiesterase inhibitor (PDEI) has been tried in 2 situations mainly. One is the use of the PDEI as a bridge to $\beta$-blocker therapy in a patient with severe $\mathrm{HF},{ }^{5}$ and the other is the use of a PDEI instead of dobutamine for the inotroperequiring patient with $\mathrm{AHF}$ who is undergoing long-term $\beta$ blocker therapy. ${ }^{6}$ Chronic $\beta$-adrenergic stimulation causes adrenergic desensitization by the downregulation of $\beta$-receptors and blunted post-receptor responses (eg, increase in inhibitory $\mathrm{G}$ proteins). Therefore, the inotropic response is blunted not only to dobutamine but also to milrinone in the failing heart. Beta-blocker therapy is reported to restore the blunted inotropic response to milrinone, independent of $\beta$-receptors. ${ }^{7}$

The current study reports that remarkable hemodynamic improvement was observed when landiolol was added to milrinone in patients with AHF. This combination therapy could be a new valuable option for the treatment of AHF. However, the characteristics of the study subjects must be taken into account because the pathophysiology of AHF is heterogeneous in nature. The study subjects were patients with systolic HF (ejection fraction $=24 \pm 7 \%$ ), and had the following characteristics: (1) NYHA class IV and Forrester subset IV, (2) preserved SBP $(122 \pm 33 \mathrm{mmHg}),(3)$ moderate increase in systemic vascular resistance $(\mathrm{SVR})\left(\approx 1,800\right.$ dynes $\left.\cdot \mathrm{s}^{-1} \cdot \mathrm{cm}^{-5}\right)$, (4) complication of pulsus alternans in $50 \%$ of subjects, and above all, (5) sinus tachycardia (107 \pm 12 beats/min). Appropriate medications should be selected by taking these patients characteristics into consideration.

Nohria et al propose categorizing patients with AHF according to the bedside noninvasive hemodynamic profile to guide and monitor therapy. ${ }^{8}$ Two fundamental hemodynamic abnormalities relate to presence or absence of elevated filling pressures (wet or dry) and perfusion that is adequate or critically limited (warm or cold). Because one piece of evidence for low perfusion (cold) is pulsus alternans, the clinical profile of the subjects in the study by Kobayashi et $\mathrm{al}^{4}$ may be classified as Class C, namely wet and cold (or lukewarm). Although this profile is considered to be compatible with the characteristics of patients in the OPTIME-CHF trial, SBP and HR were slight higher in the current study. In patients with such characteristics, diuretics and common vasodilators are often insufficient to improve hemodynamics (eg, decrease pulmonary capillary wedge pressure (PCWP) and increase cardiac output). SVR is another useful guide for selecting the appropriate medication or dose in patients with systolic HF. ${ }^{9}$ Milrinone is often needed to improve hemodynamics when SVR is moderately increased. In fact, intravenous administration of milrinone for $4 \mathrm{~h}$ definitely improved hemodynamics in these "wet and luke-

The opinions expressed in this article are not necessarily those of the editors or of the Japanese Circulation Society.

Received May 15, 2012; accepted May 17, 2012; released online May 31, 2012

Division of Cardiology, National Hospital Organization Osaka National Hospital, Osaka, Japan

Mailing address: Yoshio Yasumura, MD, PhD, Division of Cardiology, National Hospital Organization Osaka National Hospital, Osaka,

Japan. E-mail: yasumura@onh.go.jp

ISSN-1346-9843 doi:10.1253/circj.CJ-12-0655

All rights are reserved to the Japanese Circulation Society. For permissions, please e-mail: cj@j-circ.or.jp 
warm" patients. A notable feature of the study subjects was that tachycardia was sustained even after milrinone improved their hemodynamics.

Although HR usually decreases when symptoms and hemodynamics are improved by initial treatment of AHF, HR sometimes remains high in some patients. From the pathophysiological point of view, tachycardia increases energy expenditure, decreases blood supply by shortening diastole, and deteriorates both the in vivo ${ }^{10}$ and in vitro ${ }^{11}$ force-frequency associations. Furthermore, HR is directly related to ventricular elastance and ventricular loading conditions. ${ }^{12}$ Therefore, HR reduction is expected to unload and produce favorable effects on the left ventricle in patients with AHF. However, because many drugs that have the property of negative chronotropism also have the property of negative inotorpism, HR cannot always be decreased sufficiently in patients with AHF. Although the selective If inhibitor, ivabradine, reduces HR with no other apparent direct cardiovascular effects, data for the clinical application of ivabradine for AHF are still limited. Kobayashi et al show that $1.5 \mu \mathrm{g} \cdot \mathrm{kg}^{-1} \cdot \mathrm{min}^{-1}$ of landiolol reduced HR and PCWP without reducing SBP and the cardiac index (CI). However, 3-6 $\mu \mathrm{g} \cdot \mathrm{kg}^{-1} \cdot \mathrm{min}^{-1}$ of landiolol also reduced SBP and CI, which suggests that the negative inotropic effect of landiolol was in action at these doses. These findings suggests that in AHF patients whose hemodynamics and rhythm characteristics are classified as "wet and lukewarm" with sinus tachycardia, $1.5 \mu \mathrm{g} \cdot \mathrm{kg}^{-1} \cdot \mathrm{min}^{-1}$ landiolol acts as a negative chronotropic agent, with improved hemodynamics under the dose of 0.25 $0.5 \mu \mathrm{g} \cdot \mathrm{kg}^{-1} \cdot \mathrm{min}^{-1}$ of milrinone.

Pulsus alternans is evidence for low perfusion (cold) as mentioned before. In patients with clinical hypoperfusion, it is usually necessary to reduce afterload or enhance contractility. Interestingly, the addition of landiolol eliminated pulsus alternans. Although pulsus alternans is observed in many clinical conditions, it is often observed in patients with tachycardia and severe left ventricular dysfunction. ${ }^{13}$ The precise mechanism of pulsus alternans and its clinical implication remain unclear. Experimental studies suggest that the primary cause of pulsus alternans is abnormal $\mathrm{Ca}^{2+}$ handling with HR dependency. ${ }^{14,15}$ Further studies are required to elucidate whether the elimination of pulsus alternans by landiolol was caused by a reduction in $\mathrm{HR}$ or by its $\beta_{1}$-blocking effect on $\mathrm{Ca}^{2+}$ handling.

In the OPTIME-CHF trial, the prognosis of patients with AHF did not improve with milrinone treatment. From the results of both Kobayashi et al's and the OPTIME-HF studies, landiolol alone may be insufficient to improve hemodynamics at low doses and may even deteriorate cardiac function at moderate or high doses sufficient to reduce HR. On the other hand, milrinone has a potential cardiotoxic effect of increasing cAMP despite the hemodynamic improvement. Coadministration of these drugs may offset and eliminate the deficit of each other. Further studies are required to assess whether coadministra- tion of these drugs improves the outcome and becomes a beneficial strategy for the treatment of AHF, especially in a particular subgroup of patients, such as "wet and lukewarm" with sinus tachycardia.

\section{References}

1. Abraham WT, Adams KF, Fonarow GC, Costanzo MR, Berkowitz RL, LeJemtel TH, et al; ADHERE Study Group. In-hospital mortality in patients with acute decompensated heart failure requiring intravenous vasoactive medications: An analysis from the Acute Decompensated Heart Failure National Registry (ADHERE). J Am Coll Cardiol 2005; 46: 57-64.

2. Cuffe MS, Califf RM, Adams KF Jr, Benza R, Bourge R, Colucci WS, et al; Outcomes of a Prospective Trial of Intravenous Milrinone for Exacerbations of Chronic Heart Failure (OPTIME-CHF) Investigators. Short-term intravenous milrinone for acute exacerbation of chronic heart failure: A randomized controlled trial. JAMA 2002; 287: $1541-1547$.

3. Elkayam U, Tasissa G, Binanay C, Stevenson LW, Gheorghiade M, Warnica JW, et al. Use and impact of inotropes and vasodilator therapy in hospitalized patients with severe heart failure. Am Heart $J$ 2007; 153: $98-104$.

4. Kobayashi S, Susa T, Tanaka T, Murakami W, Fukuta S, Okuda S, et al. Low-dose $\beta$-blocker in combination with milrinone safely improves cardiac function and eliminates pulsus alternans in patients with acute decompensated heart failure. Circ J 2012; 76: 1646-1653.

5. Yoshikawa T, Baba A, Suzuki M, Yokozuka H, Okada Y, Nagami K, et al. Effectiveness of carvedilol alone versus carvedilol + pimobendan for severe congestive heart failure. Am J Cardiol 2000; 85: $1495-1497$.

6. Bristow MR, Shakar SF, Linseman JV, Lowes BD. Inotropes and $\beta$-blockers: Is there a need for new guidelines? J Card Fail 2001; 7: $8-12$.

7. Bohm M, Deutsch HJ, Hartmann D, Rosée KL, Stäblein A. Improvement of postreceptor events by metprolol treatment in patients with chronic heart failure. J Am Coll Cardiol 1997; 30: $992-996$.

8. Thomas SS, Nohria A. Hemodynamic classification of acute heart failure and their clinical application. Circ J 2012; 76: 278-286.

9. Watanabe A, Hashimura K, Hayashida H, Kato TS, Yokoyama H, Kanzaki H, et al. Noninvasive evaluation of systemic vascular resistance and cardiac output would help tailor optimal drug selection in acute decompensated heart failure. Eur J Heart Fail 2009; 8: A713.

10. Mulder P, Barbier S, Chagraoui A, Richard V, Henry JP, Lallemand $F$, et al. Long-term HR reduction induced by the selective $I_{\mathrm{f}}$ current inhibitor ivabradine improves left ventricular function and intrinsic myocardial structure in congestive heart failure. Circulation 2004; 109: $1674-1679$.

11. Mulleri LA, Hasenfuss G, Leavitt B, Allen PD, Alpert NR. Altered myocardial force-frequency relation in human heart failure. Circulation 1992; 85: 1743-1750.

12. Kelly RP, Ting CT, Yang TM, Liu CP, Maughan WL, Chang MS, et al. Effective arterial elastance as index of arterial vascular load in human. Circulation 1992; 86: 513-521.

13. Kodama M, Kato K, Hirono S, Okura Y, Hanawa H, Ito M, et al. Mechanical alternans in patients with chronic heart failure. $J$ Card Fail 2001; 7: 138-145.

14. Kihara Y, Motgan JP. Abnormal Ca2+ handling is the primary cause of mechanical alternans: Study in ferret ventricular muscle. Am J Physiol 1991; 261: H1746-H1755.

15. Narayan P, McCune SA, Robitaille PML, Hohl CM, Altschuld RA. Mechanical alternans and the force-frequency relationship in failing rat hearts. J Moll Cell Cardiol 1995; 27: 523-530. 